16

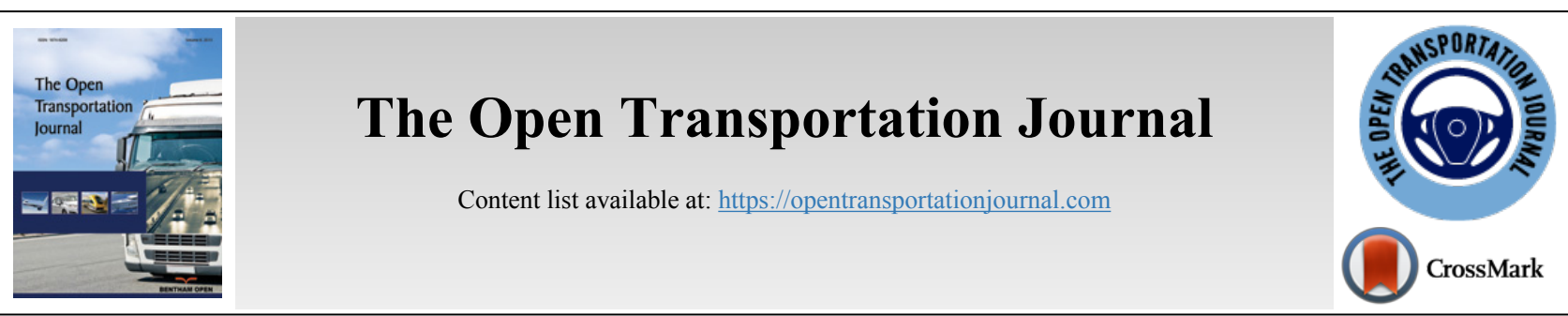

RESEARCH ARTICLE

\title{
Organization Leadership in the Automobile Industry: Knowledge Management and Intellectual Capital
}

Olga A. Shvetsova ${ }^{1, *}$, Patchara Tanubamrungsuk ${ }^{2}$ and Sangkon Lee ${ }^{1}$

${ }^{I}$ School of Industrial Management, Korea University of Technology and Education (KOREATECH), Chungjeol-ro, Byeongjeol-ro, Cheonan City, South Korea

${ }^{2}$ Danone Specialized Nutrition (Thailand) Co., Ltd, Samutprakarn, Thailand

\begin{abstract}
:
Background:

Currently, the issue of a company's innovative and competitive development is relevant in all areas of activity. The automobile industry, having innovative component as one of the development vectors, is faced with the task of achieving high competitiveness through active innovative learnings. This direction is influenced by Knowledge Management (KM) factors, which have a strong impact on the organizational leadership actions of automobile corporations.

The automobile industry in Thailand is considered successful due to fast-driven KM and technology transfer activities. Unfortunately, the growth of the Thai auto industry is directly dependent on the performance of the offices of large international leading corporations; therefore, whether the Thai auto industry will be able to maintain the same marketing position through its own knowledge and technological capabilities is a question.

This study analyzes the impact of KM-based organizational leadership in the automotive industry in Thailand using a Korean case study. Our research analyzed the knowledge-driven aspects of the automobile industry of Thailand and South Korea to identify the key factors that have a direct impact on competitiveness through the organizational leadership actions in these two countries.
\end{abstract}

Objective:

The study aims at investigating KM factors that influence the organizational leadership development of Korean and Thai automotive companies and evaluating their interdependence using the Cronbach alpha test.

Methods:

This research is based on statistical data and considers the specifics of the studied industry. It has limitations and uses quantitative data to generate results. The main source of data collection is open source. The test results for each component are organized according to the Cronbach alpha test.

Results:

Two automobile corporations from the Asian region were investigated. The application of organizational leadership in the technological field of automobile companies and knowledge transferring processes was found; an interdependence between the KM and organizational leadership was discovered as a result.

Conclusion:

Organization leadership could be used as an application for KM process development within the technological area of automobile companies. These findings can be used by managers to develop strategic programs to improve the knowledge transferring process and the organizational leadership in Asian automobile companies.

Keywords: Organizational leadership, Automobile industry, Cronbach alpha test, Knowledge management, Intellectual capital, Asian region.

\begin{tabular}{|l|l|l|l|}
\hline Article History & Received: July 30, 2020 & Revised: December 20, 2020 & Accepted: January 20, 2021 \\
\hline
\end{tabular}

\section{INTRODUCTION}

In an era of real change in the global economy, automotive organizations must be able to respond to abrupt environmental changes; this training can be carried out on a voluntary basis, limited to technology and equipment. In fact, automotive organizations must quickly and efficiently reconfigure their 
valuable human resources [1]. In addition, this transformation requires a combination of convergent, divergent, and creative thinking from both managers and key personnel. In other words, as the new external environment develops, organizations undergo changes, and internal competencies and knowledge develop; all these processes are much more complicated. Even the level of knowledge as a valuable asset is currently under threat because the very structure and types of knowledge are changing. This is why organizational leadership helps to gain required competencies and values.

The automotive industry in Thailand has a successful history. It plays an important role in the national economy and every year strengthens its position as the center of auto production in Southeast Asia. Home to world-class automobiles such as Ford, Toyota, and Nissan, Thailand is known as "Detroit of Southeast Asia". However, the growth of the industry depends on the productivity of Transnational Corporations (TNCs), so there are high risks regarding whether the Thai auto industry can maintain its previous technological and economic positions only with its own technological capabilities.

This case study uses a qualitative method to analyze both the Thai and Korean auto industries since 1960, with the aim of analyzing and comparing the Thai auto industry and the Korean auto industry in the development and transformation of knowledge. This article analyzes the dynamic process of technology learning and the formation of key knowledge in industries using the following structures: the global structure of the technological environment, the structure of the institutional environment, and the structure of dynamic technology learning.

Over more than six decades, the automotive industry has evolved from an agricultural economy to a fast-growing manufacturing economy in many developing countries, including South Korea and Thailand [2]. At the initial stage, South Korea and Thailand did not have their own accumulated technological capabilities for production. The Government's scientific policy has played a key role in the development of the industry in both countries [3,4]. The dynamic development of the automotive industry in Korea is a success story that sets an example of the rebirth of the catch-up economy into a leading global manufacturer with competitive knowledge. The South Korean auto industry has proven its ability and commitment to produce its own national cars. Korea has established and maintained a unique and independent human resources strategy for the automotive industry. An independent national strategy protected local firms from overseas TNCs that took control of the industry. The country has invested in Research and Development (R\&D) for product development and has relinquished management control in a joint venture with TNCs, thereby accelerating the process of creating its own core competencies [5].

In order to successfully build a Knowledge Management System (KMS) in an organization, it is necessary to take into account that knowledge consists of various components (indi-

\footnotetext{
* Address correspondence to this author at the School of Industrial Management, Korea University of Technology and Education (KOREATECH), 1600 Chungjeol-ro, Byeongjeol-ro, Cheonan City, South Korea; Tel: +82-1099969553; E-mail:vshvetsova57@gmail.com
}

vidual, group, and organizational). Table $\mathbf{1}$ shows the categories of knowledge, their dependent and causal elements, and the structural components that are generally known or necessary in an organization.

This classification introduces the core of the KMS. It is obvious that, in the case of ineffective work of managers, most of this knowledge will certainly be lost as a result of these changes. In this case, it is imperative to identify implicit (hidden) knowledge, transform it into explicit knowledge, and inform management decisions [6]. Therefore, there has been a growing attempt in order to maintain a good level of knowledge in the form of a knowledge-based economy, which is in fact one of the most critical duties of automotive organizations. That is why organizations have made attempts to become learning organizations [7].

Every modern automotive company, facing rapid changes in the industry, tries to maintain the established competitive advantage. In such a situation, there are two ways to maintain competitive advantages: changing the existing strategy or completely replacing it. Automotive companies have become equipped with the latest technology to be efficient and effective under new conditions [11]. However, realizing the importance of flexible knowledge, they have decided to combine human capital and accumulated knowledge with the production of high technologies. According to K.D. Lawrence et al. (2016), in this regard, organizations began to use IT and high technology together with innovation to achieve efficiency [12]. In this approach, the effectiveness turned out to be weak since the need to combine the type of knowledge with the types of innovations produced was not taken into account, so there was no added value over the long term. It was then that automotive companies realized that, in order to make progress, emphasis must be placed on other core values, such as organizational culture, human capital, and intellectual potential.

Knowledge management is essential for the development of organizational leadership and product innovation, especially in the automotive industry. The need to create a flexible internal environment conducive to open internal entrepreneurship and individual commitment to stable corporate creativity has also been mentioned in the previous literature [13]. A balanced (in combination with environmental conditions) organizational environment is very important for interprofessional activity, as it is driven by the goal of the prosperity of innovative human capital. It requires behavioral models for innovative ideas that translate new knowledge into the service industry, operational and management processes, an organizational structure, and process customization [14].

According to H. Dimitriou and R. Gackenheimer (2011), there are several important elements of creating a suitable intra-organizational environment and achieving organizational leadership focused on innovation [15]. These elements include leadership motivation to build, promoting human capital and generating new business ideas while allocating free time, a comfortable organizational structure to freely advance knowledge of innovative human capital, proper use of corporate culture, an understanding strategy, and tolerance for taking risks. It has been emphasized that the automotive organization must benefit from the ability of its employees to innovate and share knowledge in order to transform the organization and make it more competitive [16]. 
Table 1. Knowledge categories (adopted for the automotive industry).

\begin{tabular}{|c|c|c|c|c|}
\hline Source/References & Sample Values/Attributes & Description & Category & $\begin{array}{l}\text { Example from the } \\
\text { Automotive Industry }\end{array}$ \\
\hline $\begin{array}{c}\text { Thalmann (2011), Pirkkalainen et } \\
\text { al. (2010) [8] }\end{array}$ & $\begin{array}{c}\text { Subject area } \\
\text { Type } \\
\text { Representation/codification } \\
\text { Culture specifics }\end{array}$ & $\begin{array}{l}\text { Description of } \\
\text { knowledge areas of an } \\
\text { organization }\end{array}$ & $\begin{array}{c}\text { Knowledge } \\
\text { element }\end{array}$ & $\begin{array}{c}\text { Negotiation with } \\
\text { suppliers and distributors }\end{array}$ \\
\hline $\begin{array}{c}\text { Ryle (1949), Polanyi (1966), } \\
\text { Nonaka and Hansen et al. (1995) } \\
{[9]}\end{array}$ & $\begin{array}{c}\text { Knowing that } / \text { knowing how } \\
\text { Tacit/implicit/explicit } \\
\text { Knowledge and object/knowledge is a } \\
\text { process } \\
\text { Importance and } \\
\text { Complexity of } \\
\text { Group (team organization) }\end{array}$ & What kind of knowledge & Knowledge type & $\begin{array}{c}\text { Contract discussion, legal } \\
\text { knowledge }\end{array}$ \\
\hline Kalz et al. (2010) [10] & $\begin{array}{c}\text { Problem description, } \\
\text { Context } \\
\text { Related knowledge, competencies, actors }\end{array}$ & $\begin{array}{l}\text { Problems to which } \\
\text { knowledge is applied }\end{array}$ & Problem & Sales, delivery, IT \\
\hline
\end{tabular}

\section{KNOWLEDGE MANAGEMENT IN THE AUTOMOBILE INDUSTRY: A LITERATURE REVIEW}

\subsection{A Revolutionary Look at Knowledge Management}

Modern problems of reducing the impact of direct globalization on local and regional markets require managers to think about new management models, including those related to KMSs and technology management. According to K.D. Lawrence (2017) [17], these challenges are as follows:

(1) Human-oriented factors (culture, people, and leadership): Humans work as well as collaborate and communicate based on culture (both organizational and ethnic, such as a regional/national culture), so typical Knowledge Management (KM) activities such as knowledge sharing are strongly influenced.

(2) Organization (process and structures): Organizational processes also differ depending on the organizational and geographic culture. Obviously, it is necessary to coordinate $\mathrm{KM}$ processes in distributed automotive organizations and between organizations with different organizational and ethnic cultures.

(3) Technology (infrastructure and applications): Technology infrastructures also differ in different countries. This acceptance of applications is also dependent on preferences (e.g., how technologies are accepted, which technological networks are preferred in this industry in this country).

(4) Management system, which includes elements, parameters of assessment and measurement tools: Approaches to management change depending on the policy of corporate culture and ethics. Therefore, any KM methods should be combined with a chosen strategy for managing the automotive organization as a whole [17].

In order to serve customers flawlessly in such a changing environment and consolidate their position in the business, companies must shorten production cycle times, operate with minimal costs in fixed assets, reduce overhead costs (personnel, inventory, and infrastructure), reduce product development time, improve service customers, empower employees, drive productive innovation, and produce high- quality products. At the same time, automotive companies need to increase the flexibility and adaptability of organizational design, collect relevant information, create effective knowledge, share it, and constantly learn. All this is impossible without close and skillful attention to the creation, renewal, availability, quality and use of knowledge by all employees and project teams who create innovations at work (in the internal environment) and in the market (in the external environment).

In fact, according to Roos J. and Roos J. (1997), employees of organizations can create intellectual capital using the tools of meritocracy, which is based on their attitude towards the result and their intellectual flexibility [18]. Basic and necessary competencies related to education and experience, and intellectual dexterity, as a key modern competence, prepare a person to easily perceive changes, quickly adapt to them, and find innovative solutions in various difficult situations (Lank, 2017) [19]. Another approach says that the human capital of an organization includes the skills and knowledge needed to solve problems and a variety of leadership styles (Brooking, 2016) [20]. The key issue is that human capital is formed only on the basis of intellectual assets that need to be extracted or created, and if employees are properly motivated to share their knowledge and experience, this can significantly increase their level of efficiency and lead to an increase in commercial results (K. Natsuda and J. Toburn., 2011) [21]. Since such experience and knowledge is something abstract in the minds of every employee of the automotive organization, then any organization striving for success must manage them well in order to activate them and use them to create value in the market.

KMSs are designed to manage the knowledge of an organization. W.A. Bhatti et al. (2011) emphasize that KMSs are, first of all, IT systems designed to support or improve the processes of creating, storing/retrieving, transferring, and applying knowledge [22].

According to these authors, there are two approaches to building KMSs: a process (task-based) approach and an infrastructure (general) approach. The process approach focuses on the use of knowledge within a certain process, task, or project to increase their private and general efficiency. This approach determines the needs of the process only for 
information and knowledge directly related to the process. The infrastructure (general) approach is used when the organization is well structured and has common strategic objectives in knowledge and technology management. The process of identifying key competencies that are able to determine the leading organizational functions and identify tasks in the field of KM comes to the fore. The approach uses the network bandwidth, its structure, and the way the database is organized and aims to form a classification of knowledge and information.

Both approaches are rational and can be used to create a complete KMS. The process approach supports specific work activities, while the infrastructural, or generic, approach consolidates organizational knowledge into a single system that can be used for the tasks of the entire organization, not just the tasks of the process or project. Most interesting is the approach of the Knowledge Habitants of Charles (1989), which supports the concept of a dual approach, proposing to develop an organization-wide KMS to integrate various task-/processbased KMSs into a single environment and integrated system [23]. After implementing the KMSs, regardless of the approach and classification, it is necessary to determine the success or effectiveness of the chosen strategy by looking back at the rate of change in the external environment. J. Guimon (2017) lists three reasons for measuring the success of a KMS:

\section{To provide a basis for company valuation;}

2. To stimulate management to focus on what is important;

3. To justify investments in KM activities [24].

It is known that there are two main types of knowledge: implicit and explicit. Implicit knowledge is difficult to articulate and express in words, text, or pictures and therefore requires more management effort. Explicit knowledge is content that has been recorded in any tangible form, such as words, audio recordings, or images. Automotive companies most often develop their own explicit knowledge bases that are protected from outside use.

There is also a kind of paradox here: It is usually a little more difficult for highly qualified and experienced personnel to articulate their ideas and knowledge. Newbies, on the other hand, are more likely to easily articulate what they are trying to do because they usually follow the instructions for the process and do not have enough negative experience with any innovative implementation, which is the reason for the decrease in motivation. A popular misconception of many managers and authors is that $\mathrm{KM}$ focuses on displaying what is implicit in more explicit or tangible forms, and then stores or implements those forms somewhere, usually in some form of intranet or knowledge portal. However, any knowledge has its own expiration date, so it should not only be stored, but also changed and improved depending on the needs of the external environment.

$\mathrm{KM}$ is, in fact, a systematic activity throughout the organization, designed to integrate the process of coordination of competencies, which includes the creation, exchange, storage, and application of knowledge to achieve broad organizational goals (M. J. Gallivan, 2011) [25]. Although different points of view have been given on the KM process, the authors adhere to the basic concept of the KM process, which can be summarized in several stages as follows:

1. Creation of knowledge. Knowledge is a secondary product of experience and skill. Explicit knowledge is created when people make an effort to find a new way to accomplish their tasks or to solve a problem, and sometimes to prevent it from occurring. Knowledge is then classified into new categories and synthesized to create new explicit knowledge. The creation of this kind is the result of social interactions and effective communication strategies (D. Pojani and D. Stead, 2015) [26].

2. Restoration of knowledge. Knowledge needs to be preserved and restored in the organization. It is usually recovered in documents, databases, and key organizational processes.

3. Application of knowledge. Knowledge by itself has no value if it is not used. When it is used in an organization to accomplish and facilitate tasks in a specific way, then it is considered valuable and contributes to the creation of core competencies and competitive advantages.

4. Transfer of knowledge. In fact, it is the process of transferring knowledge in an organization between processes and people. Dissemination occurs throughout the organization, among employees and between organizations, when they use any communication channels.

\subsection{Organization Leadership and Transferring Innovations}

It should be noted that a systematic focus on the three basic principles of management is the foundation of any successful innovative organization. First, innovation must be part of the main strategic planning process (so far, only a few global automotive companies have succeeded). Only with this approach can a successful motivating environment for innovation be created, as well as managed, monitored, and measured. All of these processes are embedded in a key element of a growth-oriented strategy. Second, managers acquire existing (and often untapped) opportunities for innovation without wasting resources on new change programs that reduce the effectiveness of ordinary work. At the same time, they create conditions for the emergence and dynamic development of organizational innovation networks. Third, key personnel can make clear decisions to promote a culture of innovation based on employee trust and knowledge transfer from one competence center to another. If such an organizational culture is created, the staff realizes that their ideas are perceived and appreciated, and that they can freely share ideas and, together with management, find ways to solve problems (C. Cho, 2014) [27].

Since new ideas always generate other ideas as part of a network of interaction, organizational networks of specialists allow the creation of whole cycles of innovation. Moreover, effective networks enable people with different knowledge and problem-solving techniques to leverage the synergistic effect of ideas overlapping. Therefore, by focusing on getting the maximum result from innovation networks, the management team can achieve more based on the available resources without launching large-scale transformation programs, which 
significantly saves resources [28].

An analysis of existing innovation networks in a company helps management personnel analyze their characteristics (frequency of cooperation, degree of cross-functional interaction of network participants, etc.). Moreover, such interaction allows us to identify people who are most actively transmitting information and knowledge. Such information can greatly help in building effective innovation networks: managers can better understand the behavioral motives of employees and groups and create the most effective workforces.

We have described several formalized organizational mechanisms for using leadership skills to drive innovation. If the company's management is able to apply these mechanisms to solve specific problems, then it usually achieves competitive results. Leading companies use different methods of building an innovation culture.

1. Dissemination of the idea of innovative development among top-level personnel. It is great when the head of an enterprise takes innovation responsibly and holds regular meetings on innovation. However, this is not enough. All managers must agree that driving innovation is a key part of the company's strategy in order to determine how their personal goals align with innovation objectives and how to drive innovation through their own example and how to motivate middle managers.

2. Transformation of the most successful managers into leaders of the innovation process. This means that the organization needs to evaluate and help managers strengthen their mentoring and mediation skills so that they can develop their teams more effectively through effective workforce organization. As a result, networks will become more efficient.

3. Create opportunities for guided experimentation and quick success. Unsurprisingly, this approach is the best for launching a change program in large organizations. The ability to quickly achieve concrete success is even more important in terms of innovation: people need to see real results and participate in the change in order to get down to business quickly and learn as you go, select an innovative topic or area, and create small project teams.

Today's large automotive corporations are competitors if they demonstrate an ability to manage change, including creating dynamic synergies of new technology applications and, accordingly, the manifestation of the rapid growth of the potential of new technologies. At the same time, the key task of reducing costs while maintaining the level of quality and competitiveness remains. The ability to combine the capabilities of technology with the needs of the market in the face of rapid change and an uncertain environment is the key to the future prosperity of a particular business, requiring high agility from the company.

Technology transfer is a process based on an accurate and reliable assessment of the commercialization potential of a development. Usually, the initiator of the transfer (the author or the owner of the technology) believes in the exaggerated value of the invention, so the technology audit is very important at the first stage of the transfer process. The selection of assessment criteria is determined by the purpose of the audit and varies by industry, region, and specific environmental conditions. Technology audit involves determining the technical level and assessing compliance with industry development trends, assessing the level of patent protection and patent purity.

Some authors describe and demonstrate the possibility of influencing the assessment of knowledge of other components of the organization's management system. Therefore, there are many models and approaches to assessing knowledge, but they should be chosen depending on the strategic objectives. Widespread discussion of the importance of knowledge in managing an organization followed the work of Sveiby (1997) in Sweden [29]. This author first raised the question of the influence of knowledge on the strategic assets of the organization and revealed the various effects of their assessment on the behavioral model of the organization. Since then, other authors have supported these approaches and have begun to develop various theories of KM in organizations [30].

\section{METHODOLOGY}

In accordance with modern scientific sources, the elements of the KMS are considered by managers and scientists as dependent variables, and the results of the functioning of such a system, that is, the processes of knowledge production and knowledge capitals, are considered as independent variables. A conceptual model for this study is shown in Fig. (1).

Having studied the literature, the authors put forward a hypothesis that the knowledge capital of an organization has a serious positive impact on the development of organizational leadership of an automotive company in the implementation of the process of transferring innovations and technologies.

The research methodology is based on quantitative data obtained in the public domain and limited in time. Moreover, employees of Korean and Thai automotive manufacturing companies were interviewed, their technology and knowledge strategies were analyzed, and experts were involved.

Cronbach's alpha, $\alpha$ (or coefficient alpha), developed by Lee Cronbach in 1951, measures reliability or internal consistency. "Reliability" is how well a test measures what it should. For example, a company might give a job satisfaction survey to their employees. High reliability means it measures job satisfaction, while low reliability means it measures something else (or possibly nothing at all).

Cronbach's alpha tests to see if multiple-question Likert scale surveys are reliable. These questions measure latent variables, hidden or unobservable variables, such as a person's conscientiousness, neurosis, or openness. These are very difficult to measure in real life. Cronbach's alpha will determine whether the test designed is accurately measuring the variable of interest. 

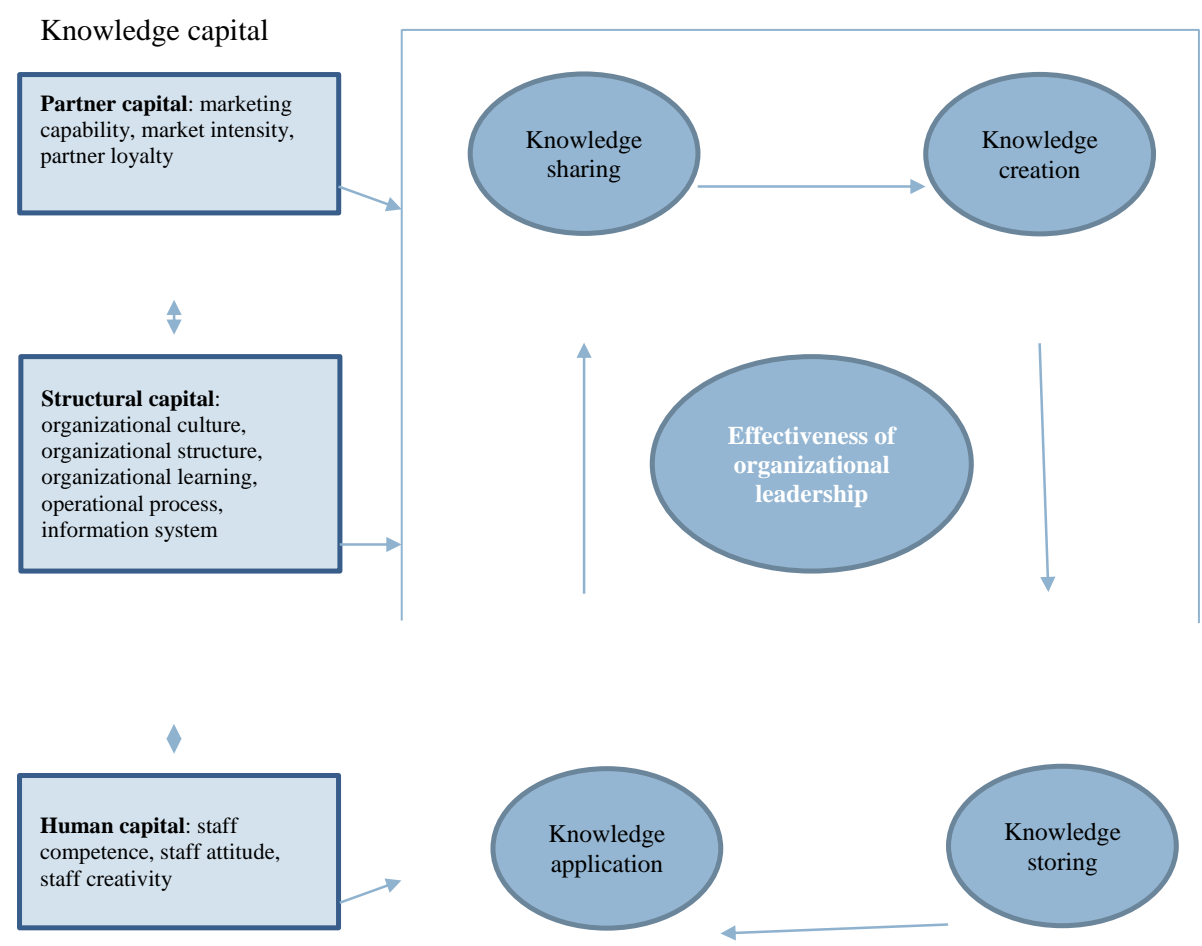

Fig. (1). Framework of the research.

A high level of alpha may mean that the items in the test are highly correlated. However, $\alpha$ is also sensitive to the number of items in a test. A larger number of items can result in a larger $\alpha$, and a smaller number of items in a smaller $\alpha$. If alpha is high, this may mean redundant questions (i.e., they are asking for the same information). A low value for alpha may mean that there are not enough questions on the test. Adding more relevant items to the test can increase alpha. Poor interrelatedness between test questions can also cause low values, as can measuring more than one latent variable.

Confusion often surrounds the causes for high and low alpha scores. This can result in incorrectly discarded tests or tests wrongly labeled as untrustworthy. Psychometrics professor Mohsen Tavakol and medical education professor Reg Dennick suggest that improving one's knowledge about internal consistency and unidimensionality will lead to the correct use of Cronbach's alpha.

Unidimensionality in Cronbach's alpha assumes that questions are only measuring one latent variable or dimension. If more than one dimension is measured (either knowingly or unknowingly), the test result may be meaningless. The test could be broken up into parts, measuring a different latent variable or dimension with each part. If whether a test is unidimensional or not is unclear, Factor Analysis can be run to identify the test's dimensions.

Cronbach's alpha can be written as a function of the number of test items and the average inter-correlation among the items. Below, for conceptual purposes, we show Formula 1 for Cronbach's alpha:

$$
\alpha=\frac{N \bar{c}}{\bar{v}+(N-1) \bar{c}}
$$

Here, $\mathrm{N}$ is equal to the number of items, $\mathrm{c}^{-}$is the average interitem covariance among the items, and $\mathrm{v}^{-}$is the average variance.

A rule of thumb for interpreting alpha for dichotomous questions (i.e., questions with two possible answers) or Likert scale questions is as follows:

\begin{tabular}{|l|l|}
\hline Cronbach's alpha & Internal consistency \\
\hline$\alpha \geq 0.9$ & Excellent \\
\hline $0.9>a \geq 0.8$ & Good \\
\hline $0.8>a \geq 0.7$ & Acceptable \\
\hline $0.7>a \geq 0.6$ & Questionable \\
\hline $0.6>a \geq 0.5$ & Poor \\
\hline $0.5>a$ & Unacceptable \\
\hline
\end{tabular}

In general, a score of more than 0.7 is usually okay. However, some authors suggest higher values of 0.90-0.95.

Quantitative data were collected from expert opinions and open resources; experts were invited from automotive companies and their partners, i.e., consulting agencies.

\section{DEVELOPMENT TRENDS OF THE AUTOMOBILE INDUSTRY IN THE ASIAN REGION}

\subsection{Problem Statement}

The authors selected the automotive industry in Thailand 
and South Korea for the study due to the following reasons: (a) The automotive industry in South Korea has been developing rapidly for over a decade and is one of the key industries that has contributed to the creation and transformation of new industrial knowledge to create a new development path economy. This successful example is seen as an effective model for creating a development plan for other developing countries. b) Although it took six times longer, the Thai auto industry has followed a very similar economic development path to South Korea; however, in terms of knowledge, Thailand still lags far behind. As a result, it is important to explore the path of development of industry knowledge, as well as search for improvements in innovation for the Thai automotive industry in the near future.

Over the past century, the development of the automotive industry has become one of the central areas of the global economy and has spread throughout the world. The center of the global automotive industry moved from the European continent to other parts of the world: the United States in the 1920s and to Japan in the 1980s after the oil crisis of the 1970s [30]. In the early 1980s, global car production was around 30 million units. The seven-leading auto-manufacturing countries (Japan, USA, Germany, France, Italy, UK and Canada) dominated 80 percent of global vehicle production. In the 20th century, the global automotive industry was actively influenced by globalization and increased the number of joint ventures between car manufacturers in different regions of the world, as this provided quick access to various markets. As the trend of internationalization expanded significantly, trade policies of other trade sectors affected the automotive industry, which also affected knowledge transfer. Thanks to this, many foreign car manufacturers have achieved success in local and regional markets. Japan became the first East Asian country to build and export assembly plants overseas, and then became the world's leading automaker. In the context of the increasing influence of globalization, automobile manufacturers began to hire foreign suppliers because of lower production costs, improved quality, shorter lead times for key components, and more reliable services (US International Trade Commission, 1985) [30, 31]. Demand and production grew steadily together. The bankruptcy of American Companies General Motors and Chrysler in 2009 marked the end of American leadership in the automotive industry, marking the end of the Detroit era and the end of the era of mass production in leading manufacturing industries. China is emerging as a major player in the global automotive industry thanks to huge domestic demand. After World War II, some developing countries, the so-called New Industrial Economies (NIS), tried to catch up with the developed countries by assimilating their technologies. Thus, those countries that bet on maximizing their research potential achieved rapid economic growth, and some of them reached a point where they had forged their own individual path and were then ahead of the formerly leading countries.

We propose to consider innovation as a technological learning process and the result of the effectiveness of knowledge dissemination. There are three sources of technology learning: an international source (resources), an internal source (ability), and an internal effort (motivation). South Korea acquired technology as a resource from an international source by exchanging a share of organizational capital in exchange for access to technology. For example, 12 percent of Hyundai shares were transferred to Mitsubishi Motors, and Kia transferred 20 percent to Ford in order to gain access to the technology. However, in the case of the Daewoo cooperation, the joint venture with GM initially showed significant results through successful knowledge exchange and integration into the international environment. However, without effective management oversight, Hyundai could not develop its own product to meet market needs. For this reason, Daewoo switched to a strategy of independence and increased its productivity using the internal resources already accumulated by that time. In Thailand, as in the case of Daewoo, a joint venture with foreign TNCs limited the productivity of local companies. This indirectly influenced the development of technological potential and promoted the activation of Thai companies to create their own independent strategy.

This study is based on these research questions below:

1) How does KM affect the organizational leadership of an automobile company?

2) How do knowledge and intellectual capitals depend on each other?

3) What is the role of innovative learning in the automobile industry?

\subsection{Thai Automobile Industry}

Over 50 years, Thailand proved its potential for fast development of automotive manufacturing and has become a leading global automotive production base in the Association of Southeast Asian Nations (ASEAN). From an assembler of auto components to a top automotive manufacturing and export hub, its performance achieved more than 1.98 million vehicles produced and was worth USD 27 billion in 2017. These successes also ranked the country as the best automobile producer in Southeast Asia, the $6^{\text {th }}$ best commercial vehicle producer, and the $12^{\text {th }}$ best automobile producer in the world in 2017 (Fig. 2).

The largest production consists of 960,413 pickup vehicles (48 percent), 818,440 passenger cars (41 percent), and other commercial vehicles (11 percent). In line with its ambitious EV targets, the Thai government is aiming to become the leader of The Association of Southeast Asian Nations (ASEAN) by 2025. By 2030, Thailand plans to produce more than 2,500,000 units and increase the production of electric vehicles to $30 \%$ of the total annual car production [32].

According to the Investment Council of Thailand (2019), the automotive industry is one of the most important sectors of the economy in helping to overcome the middle-income trap. The extensive economic plan for special economic zones provides more investment opportunities for foreign businesses in Thailand [33]. A full range of economic benefits and incentives for cars, engines, and parts in border areas such as Tak, Sa Keo, Mahon Phanom, and Kanchanaburi has been supported and implemented to link with the ASEAN Economic Community (AEC) [34]. 


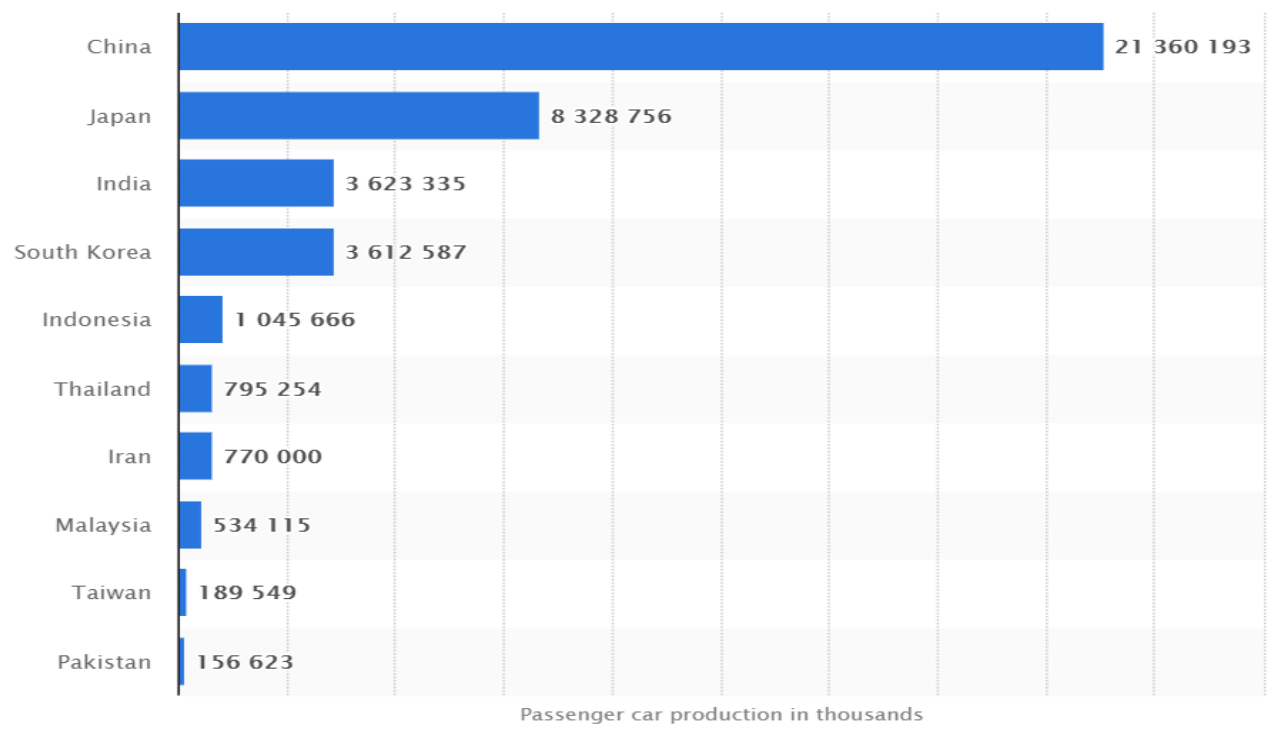

Fig. 2. Number of passenger cars produced in the Asia Pacific region in 2019, by country or region (in 1000s). Source: STATISTA, 2020 [31].

According to the Investment Council of Thailand (2017), the main research work is carried out at the R\&D and training center for car assemblers. For example, Toyota Motor supports vehicle and technology development, including product planning, engineering design, and localization. Each R\&D center carries out its own independent but market-oriented development. There are currently five automotive R\&D centers established by automotive assemblers in Thailand (Table 2). Moreover, the Thai government supports the automotive industry through the implementation of the Automotive Master Plan, setting targets for Thailand to achieve a higher added value by 2021 .

Table 2. Thailand Automobile R\&D Centers.

\begin{tabular}{|c|c|}
\hline Company & Activities \\
\hline $\begin{array}{c}\text { Toyota Motor Asia } \\
\text { Pacific Engineering and } \\
\text { Manufacturing } \\
\text { in 11 countries in Asia-Pacific, Africa, and } \\
\text { South Africa, in 4 research fields including } \\
\text { product planning, engineering design, } \\
\text { evaluation, and localization. }\end{array}$ \\
$\begin{array}{c}\text { Sissan Technical Center } \\
\text { South East Asia }\end{array}$ & $\begin{array}{c}\text { Support for car development in 6 Nissan } \\
\text { production sites across Asian countries. } \\
\text { Responsibility for all R\&D processes. }\end{array}$ \\
\hline $\begin{array}{c}\text { Isuzu Technical Center } \\
\text { of Asia }\end{array}$ & $\begin{array}{c}\text { Covers each single scope of light } \\
\text { commercial vehicle (LCV) and private } \\
\text { passenger vehicle (PPV) research and } \\
\text { development for the whole world. }\end{array}$ \\
\hline $\begin{array}{c}\text { Honda R\&D Asia } \\
\text { Pacific }\end{array}$ & $\begin{array}{c}\text { Elevated to be an automobile design and } \\
\text { R\&D center in 12 countries across Asia and } \\
\text { Oceania. }\end{array}$ \\
\hline $\begin{array}{c}\text { Mitsubishi Motors } \\
\text { Proving Ground }\end{array}$ & $\begin{array}{c}\text { First outside Japan research and } \\
\text { development proving ground. Multipurpose } \\
\text { testing. }\end{array}$ \\
\hline Source: Board of Investment, 2017 [35].
\end{tabular}

According to the Investment Council of Thailand (2017), the number of workers in the Thai auto industry in 2016 exceeded 7,000,000 persons. Thailand has 29 universities and other institutions offering educational programs in the automotive and mechanical engineering sectors. However, statistics from the National Statistical Center showed that the educational level of most workers in the automotive industry is below the university level. Although Thailand has a skilled workforce, more than half of them lack engineering skills, which are currently among the main scope of skills. The BIO forecast (2017) states that, in 2021, the percentage of highly skilled workers with a college degree will reach 61 percent of all workers in the Thai auto industry, while 27 percent will have a Bachelor's degree in engineering, and only 5 percent will have a Master's or higher. Many automotive companies in Thailand are developing their own employee training programs to help improve their competitiveness and efficiency (Investment Council of Thailand, 2017) [36]. We think this is a good way to find and manage one's own corporate knowledge.

The Thailand Automotive Institute (TAI) has developed a technology roadmap for 2012-2016 to implement a joint R\&D strategy with other organizations. The purpose of the map is to strengthen Thailand's position as a technology leader in ASEAN. The private sector creates and operates research, development, and engineering activities.

According to the ASEAN auto industry, Thailand's Investment Council has responded to strong domestic demand for electric vehicles with support, tax, and import tariff exemptions for major vehicle components, including engines and batteries. This proves the potential of the local market as a leading center for the production of Electric Vehicles (EVs) in the Southeast Asia region (ASEAN Report, 2012) [37].

\subsection{The Korean Automobile Industry}

According to Kim \& Hwang (2000), in the 1950s, the Korean government supported the chaebol system as the backbone of industrialization for ambitious export purposes. A chaebol is a large industrial conglomerate that is run and controlled by an owner or family in South Korea. A chaebol often consists of many diversified affiliates and is controlled by 
an owner whose power over the group often exceeds legal authority. The Foreign Capital Attraction Act (FCIA) has increased foreign direct investment in South Korea [38]. The purpose of attracting foreign capital in Korea was to establish a balance between payments and access to resources such as technology and knowledge. Korean car firms offered equity in exchange for access to technology and self-government because they themselves had a complex system of innovation. Moreover, the Korean government wanted to redirect limited capital resources to industries vital to long-term economic growth (Kim \& Hwang, 2000) [39]. For this reason, Korea has shifted its national economic interest towards a unique and independent strategy.

The Korean automotive industry began in the 1960s. The increase in the amount of used military equipment during the war raised the number of repair enterprises. The experience of Korean workers and their knowledge has been an important asset and an important resource for the development of the Korean auto industry. National auto parts factories such as Daewon Global and Yoosung were established in 1953. The Sibal is Korea's first assembled car from used parts. In 1955, seven Sibals were produced, and in 1957, this number increased to 459 . However, many studies have estimated that Korean automobile production began with the assembly of the Knockdown (KD), and a significant number of vehicles were produced in 1962 [40].

For decades, South Korea's automotive industry has grown exponentially and has also been an indicator of the economic growth in the East Asian region. This main industry in the country influenced other industries as well, such as electronics, advertising, financial services, and construction. The automotive industry in South Korea is currently undergoing major changes that began even before the COVID-19 period (Table 3). The South Korean government intends to produce 6.3 million fuel-electric vehicles (FCEVs) and build 1200 filling stations across the country by 2040 to reduce greenhouse gas emissions and develop energy independence. In
2018, about 32 thousand FCEVs were delivered to South Korea. In addition, as of March 2018, about 9.3 million South Koreans were using car-sharing systems [41]. The number of electric vehicles and gas stations for them is also rapidly increasing.

The Korean Automobile industry entered the foreign markets with overseas production of 1.88 million units in 2009 . Korean automobile manufacturers established local plants in many countries around the world. The purpose of Korean automobile manufacturers was to sustain growth as a worldleading auto producer. Recently, with modern technology, the Korean auto industry has focused on eco-friendly cars such as hybrid cars, electric cars, and fuel battery cars. Policy support has been enhanced to improve the quality of the industry (KSP, 2014) [42].

\section{DATA ANALYSIS AND RESULTS}

The results of testing each component in accordance with the Cronbach alpha test are as follows:

- Creating and acquiring component: 0.70 ;

- How to store knowledge: 0.78 ;

- How to share knowledge: 0.78;

- How to use knowledge: 0.79 ;

- Human capital: 0.70;

- Structural capital: 0.75 ;

- Communication capital (partnership): 0.74;

- The total expert opinion: 0.72 .

Since the Cronbach's alpha coefficient in the expert opinion is 0.7 higher than the required minimum, the objectivity and reliability of the expert opinion are confirmed. To once again check the reliability of the expert opinion, the authors additionally carried out a factor analysis of the interrelated components of the organization's management.

Table 3. Summary of the evolution of the korean automobile industry.

\begin{tabular}{|c|c|c|c|c|}
\hline Development stage & $\begin{array}{c}\text { Import Substitution } \\
(1960-1970)\end{array}$ & Internalization (1971-1990) & $\begin{array}{c}\text { Generation Stage } \\
(1990-2009)\end{array}$ & $\begin{array}{c}\text { Leading Stage (From } \\
\text { 2010) }\end{array}$ \\
\hline Characteristic & $\begin{array}{l}\text { Enhance S.K.D. assembly, } \\
\text { Localization C.K.D. } \\
\text { manufacturing. } \\
\text { SKD has been semi knocked } \\
\text { down, and CKD is completely } \\
\text { knocked down. }\end{array}$ & $\begin{array}{l}\text { Local model early production, } \\
\text { Innovative local model }\end{array}$ & $\begin{array}{l}\text { Generation of technology } \\
\text { with new engine design }\end{array}$ & $\begin{array}{l}\text { World leader - new } \\
\text { dominant design; }\end{array}$ \\
\hline $\begin{array}{l}\text { Source of } \\
\text { technology }\end{array}$ & $\begin{array}{l}\text { Technology import, joint } \\
\text { venture }\end{array}$ & $\begin{array}{l}\text { Technology import joint venture, } \\
\text { export market, in-house R\&D }\end{array}$ & $\begin{array}{l}\text { In-house R\&D, technology } \\
\text { import }\end{array}$ & $\begin{array}{l}\text { In-house and open } \\
\text { innovation }\end{array}$ \\
\hline Product & Assembly & Mass production, national car & $\begin{array}{c}\text { Indigenous model } \\
\text { development }\end{array}$ & Electric car, smart car \\
\hline Management model & Japanese and EU model & $\begin{array}{l}\text { Local model, F-F development } \\
\text { model }\end{array}$ & Local model & Local model \\
\hline Market & Domestic market orientation & Export orientation & $\begin{array}{l}\text { Moved toward strengthening } \\
\text { export capacity }\end{array}$ & International market \\
\hline Result & $\begin{array}{c}\text { Gained assembly line experience } \\
\text { with mass production }\end{array}$ & $\begin{array}{l}\text { Moved toward strengthening } \\
\text { export capacity }\end{array}$ & $\begin{array}{l}\text { Sustainable upgradation as a } \\
\text { regional base }\end{array}$ & $\begin{array}{l}\text { Maintained leading } \\
\text { position in global } \\
\text { production }\end{array}$ \\
\hline
\end{tabular}


For the study, 16 experts (middle managers and project managers) from Thai and Korean car companies were selected using a simple random sample method.

The interview process was arranged on the sample documents from each business process of the automotive company. For example, a group of experts analyzed a set of competencies and factors, which have a strong impact on the production process.

The authors used the data obtained in the process of simple sampling. These data were processed in order to identify their direct relationship; that is, they were checked simultaneously in the analysis of Structural Equation Modeling (SEM). In this study, an SEM was used to collect, analyze, and interpret the data obtained. SEM allows one to use research results to confirm or disprove a hypothesis. First, all system components are modeled, and the model's reliability is then assessed. The evaluation uses special indicators that show the ratio of the chisquare to the degree of freedom of the exponent. The degree of freedom must be determined by a value less than the acceptable level of 3, and the root-mean-square value of the approximate error must be calculated. The possible value of the permissible error should be less than 0.08 ; the Pi value must be less than 0.05 . It is also necessary to adjust the compliance index during the study, which should be greater than 0.9 .

When assessing the significance and influence of knowledge capital on the productivity of organizational leadership, the authors used a weighty factor model, and to assess the weight of this influence, the researchers used a standard organizational KM model. It is important to determine the limitations of the application of this model, which are expressed in the fact that the values should be determined at the level of 0.95 . At the same time, indicators that do not fall within the range from 1.96 to -1.96 are the most significant. This means that the indicator falling within the range from 1.96 to -1.96 has no weight and is not taken into account in further evaluation. Fig. (3) shows the impact of organizational components and their overall interactions on the production of knowledge capital.

The main hypothesis is that different organizational knowledge has a direct and positive impact on the formation of organizational leadership. The main hypothesis is supported by the following secondary hypotheses:

- Human capital has a significant impact on the formation of the organizational capital of the organization;

- Structural capital has a significant and positive impact on the implementation of a KMS in an organization;

- Communication capital has a direct and positive impact on the dissemination and strengthening of knowledge in an organization.

The authors proposed to develop a semantic model that determines the various mutual influences of all these components on the final efficiency of the organizational leadership of an automotive company. The next step was to use a standard functional model that makes it possible to assess the degree (weight) of the influence exerted by each parameter in the entire structure of relationships. (Fig. 3) shows the weights of the predicted relationships in this model.

According to the indicators presented in Table 4, one can judge the productivity of the research model.

The model fit indices allow us to assess the degree of the model's suitability for assessing interrelated options since the ratio of the chi-square to the freedom index is 2.67 , which is less than the acceptable value of 3 ; also note that the root mean square value of the approximate error $(0.039)$ is in the desired range of allowed values, and the $\mathrm{Pi}(0.0005)$ indicator shows a result that is less than the acceptable range, which is 0.05 . In accordance with the results of this model, the authors revealed a direct impact of knowledge capital on the effectiveness of organizational leadership actions since this influence has a value of 4.32 , which exceeds the value of 1.96 . The standard model (Fig. 4) is then applied to the study to assess the importance of the impact of organizational communication channels on the dissemination of knowledge in the organization.

We further hypothesized how human capital, structural capital, and relationship capital (partnership) affect the quality of existence of organizational leadership (sub-hypothesis). Thus, we first applied a meaningful model to determine the degree to which each element of knowledge capital influences management decisions. A standard model was then used that identified how each aspect affects the quality of the organization's learning. We assessed each of the subhypotheses using separate approaches and using an independent model. Since there are many scoring models, the organizers set the limits of the study to select and apply only one scoring model (using factor analysis) [46]. The generalized results of the corresponding analysis of the data for these hypotheses are presented in Table $\mathbf{5}$. The data indicated in the Table 5 will help to further process the results and draw appropriate final conclusions.

Table 4. Fittings of indexes of organizational leadership effects on knowledge management (KM).

\begin{tabular}{|c|c|c|c|}
\hline Indexes & Allowable Amount & Gained Numbers & Results \\
\hline Proportion of Chi-square to freedom degree & $\mathrm{X}^{2} / \mathrm{df}<3$ & 2.67 & Suitable fitting \\
\hline Pi value & $\mathrm{P}<0.05$ & 0.0005 & Suitable fitting \\
\hline Root mean square of approximate error (RMSEA) & $0.05<$ RMSEA $<0.08$ & 0.039 & Suitable fitting \\
\hline
\end{tabular}




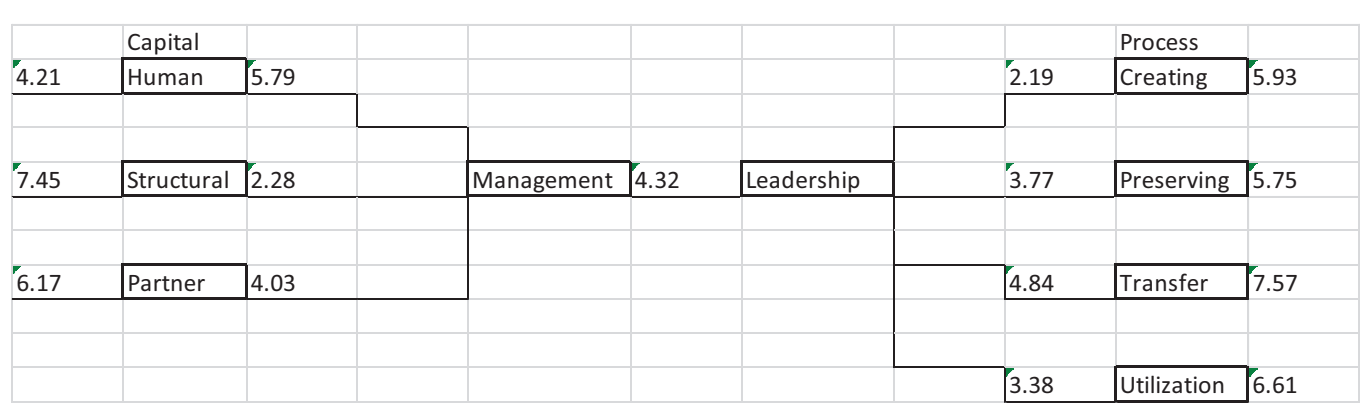

Fig 3. Ch $i$-square $=42.87, \mathrm{df}=16, \mathrm{P}$-value $=0.00005, \mathrm{RMSEA}=0.039$.

The model of KM effects on organizational leadership in standard mode.

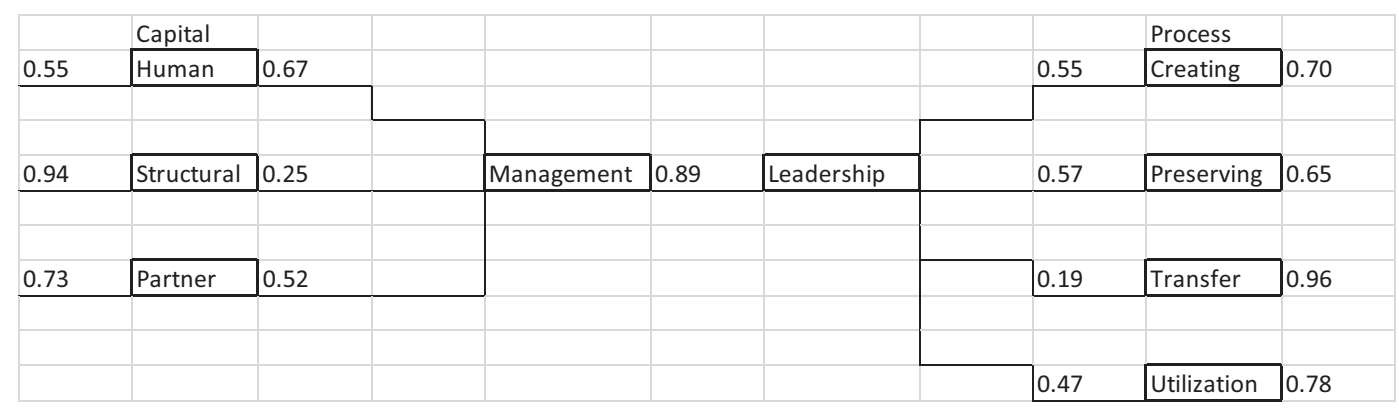

Fig (4). Chi-square $=42.87, \mathrm{df}=16, \mathrm{P}$-value $=0.00005$, RMSEA $=0.039$.

The model of Knowledge Management (KM) effects on organizational leadership in standard model.

Table 5. The results from assessing hypotheses.

\begin{tabular}{|c|c|c|c|c|}
\hline Hypothesis & Path & $\begin{array}{l}\text { Standard } \\
\text { Coefficient }\end{array}$ & $\begin{array}{c}\text { Numbers' } \\
\text { Meaningfulness }\end{array}$ & Results \\
\hline Main & $\begin{array}{l}\text { Meaningful and positive effects of KM on organizational leadership action } \\
\text { effectiveness }\end{array}$ & 0.87 & 13.00 & Confirmed \\
\hline 1 & $\begin{array}{l}\text { Meaningful and positive effects of human capitals on KM action } \\
\text { effectiveness }\end{array}$ & 0.89 & 12.30 & Confirmed \\
\hline 2 & $\begin{array}{c}\text { Meaningful and positive effects of structural capitals on KM action } \\
\text { effectiveness }\end{array}$ & 0.88 & 9.33 & Confirmed \\
\hline 3 & $\begin{array}{c}\text { Meaningful and positive effects of partner capitals on KM action } \\
\text { effectiveness }\end{array}$ & 0.54 & 7.87 & Confirmed \\
\hline
\end{tabular}

The results in Table 5 show an assessment of the importance of various components of knowledge capital, which have a direct and significant impact on the management decisions of the organization's management personnel. This statement is confirmed by the fact that the value affecting knowledge capital is not in the range from -1.96 to 1.96 . This substantiates the previously proposed hypothesis and confirms the proposed assumption that knowledge capital has a significant and positive impact on the management decisions of the organization's management. Moreover, the obtained values of the weight of the human capital indicator show that it has the greatest impact on improving the quality of management decisions of the organization (0.89).

The general factorial model, reflecting the relationship of variable components in the structural equation model, was applied within the framework of existing organizational development trajectories and strategic planning; all four assessed parameters showed significance. In accordance with the results obtained, it can be noted that improving the quality of the organization's knowledge capital directly affects the quality of organizational decision-making. It is also obvious that human capital plays a large role in the quality of decisions made by managers and managerial actions. In this regard, the authors note that significant components of human capital, influencing the process of formation and manifestation of organizational leadership, consist of competence, communication, and creativity. Confirmation of the previously stated hypothesis also justifies the formulation of important tasks in improving the quality of human capital through various training programs in order to optimize the organizational design and overall strategy. Several of the components of structural capital have been shown to be effective in the creation and development of organizational leadership: 
organizational culture, organizational structure, organizational learning, and operating procedures [46, 47]. The results obtained do not contradict previously published studies in this area and agree with the results of previous authors. It is necessary to note the positive influence of all elements of knowledge capital on the further development of organizational leadership in the literature on KM, which is consistent with our conclusions.

\section{DISCUSSION}

The effect of globalization and the latest transformation of world economic relations enhance the role of scientific research and emphasize the importance of creating and introducing new technologies, as well as mechanisms and methods of sustainable economic development, as the basis of world competitiveness for automotive organizations. One of the main components of the economic development of such companies is the transfer of technologies and knowledge, their transformation, and their development. The degree of participation of countries in this process largely determines the possibilities of their technical progress and competitiveness. In the Asian region, an active interest in technology transfer today is associated not only with the improvement of market relations in the economy but also with the leadership of countries in world markets. For the development of the economy of each country, it is necessary not only to increase the rate of transfer of unique and advanced technologies and knowledge, attracting financial resources to enhance innovation, but also to work proactively, creating economic forecasts. Moreover, the introduction of innovations in enterprises should prevent future global risks, which will allow for the creation and development of an efficient infrastructure for the commercialization and transfer of technologies (Heisig P., 2019) [47]. These days the global risk of COVID-19 requires new facilities and skills to develop new knowledge strategies. This is the task for future discussion.

The property of innovation "affordability" characterizes the ability to acquire or transfer this technology. It is associated with whoever initiates the transfer, that is the receiving party, the developer, or another person. If the initiator is also a developer, then the availability of the technology is maximized, since not only is documentation transferred, but also the knowledge characteristic of this technology. In this case, it is possible to organize the training of personnel immediately and at the lowest cost. On the contrary, for technologies that are not disclosed by the developer and are protected as a trade secret (know-how), the availability is minimal. In this case, the transfer becomes almost impossible, and the development of a special strategy and motivational program is required (Hobohm H.-C., 2014) [48].

The complexity of knowledge transfer is not clearly defined today. In general terms, this is defined as the skill level required to use and transfer technology. The more complex the technology, the higher the skill level required to use and transfer it. The property of integrity in relation to industrial technology characterizes the relationship of technology with other technologies (Davenport T.H. et al., 2009) [49].

At one time, technology providers in the automotive industry were willing to transfer technology to South Korea through foreign direct investment and foreign licensing. They had an attractive motivation. However, Korea later faced restrictions from advanced countries. Informal technical assistance was applied to reverse engineering that led to innovation. South Korea was able to acquire foreign technology. As a result, South Korea is now gaining new capacity through technology transfer from foreign sources. However, Thailand's low absorptive capacity has allowed TNCs as a technology provider to take advantage of expanding their market through foreign direct investment and become dependent on foreign direct investment. This is a major problem for the Thai auto industry.

Korea has been able to develop an independent strategy in the automotive industry. The transfer of knowledge through foreign technology can increase the level of competence and accelerate the process of training local staff through a strong bargaining power. This is exemplified by Hyundai's commitment to an independent strategy that delivers dynamic long-term learning and by Daewoo's joint venture showcasing rapid initial learning, albeit not long-term.

\section{CONCLUSION}

The conducted research proved the significant interdependence of knowledge factors and the organizational leadership actions of automobile companies. The significant impact on human capital of KMSs and the organizational leadership formulation of automobile companies was also established.

Different management practices, knowledge and different elements of intellectual capital can benefit automobile companies and maximize value for their owners, but only if they support and reinforce each other. The results show that Thai and Korean companies need to move in this direction if they want to develop their technology and knowledge cooperation successfully.

As a result of the study, a general multivariate model consisting of dependent and independent variables applicable in a model of structural equations was formed. This model was developed considering compatibility with the strategy and organizational design of automotive companies, which showed certain limitations. All the measured indicators and their relationships turned out to be significant. The authors identified the following conclusions:

1. The effect of the impact of human, organizational, and communication capital on the effectiveness of organizational actions of the leadership is positive.

2. The organizational leadership of automotive companies is the interconnection between the processes of the sociotechnological system, the efficiency of which mostly depends on the strategic constraints and conditions of the external and internal environment. The availability of quality technological and management infrastructures can help improve the quality of organizational leadership in automotive companies.

3. The central component of good organizational design and company infrastructure is the intellectual capital of the organization. 
This study made it possible to assess and confirm the positive impact of the elements of knowledge assets on the process of improving human and structural capital, as well as their positive impact on improving the quality of decisions made by management. At the same time, the further trajectory of the development of management decisions and the improvement of organizational leadership through successful knowledge transfer is determined.

To explain the influence of structural capital on organizational leadership, the following causal relationships (prerequisites) were identified: when organizational culture supports the formation, learning, development, and exchange of knowledge, it contributes to the further positive transformation of knowledge and its transformation into key competencies. In the presence of soft control in the organization, adequate organizational design, and an excellent communication environment in which every employee of the automotive organization has access to existing information and knowledge, a synergistic effect of the production and dissemination of key knowledge is triggered, which leads to a high level of competitiveness and technological success of the company. However, data and knowledge protection between independent companies is a problem. Therefore, we suggest that improving and reinforcing intangible capital can prepare the right KM structure to promote an organizational leadership system's effectiveness in an automobile organization.

Through a case study and Cronbach test, we found that human capital plays a large role in the quality of decisions made by managers and managerial actions. In this regard, significant components of human capital, influencing the process of formation and the manifestation of organizational leadership, consist of competence, communication, and creativity.

Thailand has chosen a strategy of organizing joint ventures with foreign TNCs. Local offices are dependent on the head office. As a result, Thailand is exploring technology through the strategy of the parent firm and becoming dependent on foreign direct investment.

The strong and centralized Korean government exemplifies an effective industrial policy. In addition, the establishment of a science and technology information center in South Korea has created a network of connections within the industry, leading to the diffusion of technology through effective communication. In Thailand, the role of government and technology learning support in organizations remains dependent on foreign direct investment.

Korean firms acquire and master foreign technology mainly through simulation design and move towards direct investment in R\&D. For example, Hyundai increased its investment in R\&D from $4.4 \%$ of sales in 1994 to $7 \%$ in 1995 , and this investment continued to increase afterwards. In Thailand, the company's research and development activities are controlled by a joint venture to develop more efficient functions for individual products [50].

These results can be used to make managerial decisions in the process of forming an automobile industry competitive strategy.

\section{LIMITATIONS AND FUTURE RESEARCH ORIENTATIONS}

There are some limitations to this research:

- This research is based on one case study, that is knowledge transfer between Korean and Thai companies.

- This study is focused on KM and organizational leadership, but the role of technology transfer process has not been discussed.

- Only automobile industries from the two countries are discussed.

- The period of the survey is limited to two years.

For future research, it is necessary to discuss three typical technological learning patterns in the automobile industry. Organizational design incorporates various principled decisions about the separation of work in the company and the coordination methods between different departments. Thus, the problem is the protection of intellectual assets during the knowledge transferring process. By choosing specific solutions in this area, such as involving employees in decision-making or creating cross-functional expert groups, a company can increase the efficiency of its knowledge resources. The company's unique knowledge is a source of competitive advantage, so the protection of such strategically significant knowledge is an important task of KM.

Future researchers can consider quantitative and qualitative algorithms of the knowledge transferring process for effective cooperative strategies between independent companies. The significant role of the promotion of technological innovation capabilities can be identified, and the intellectual property right of the enterprises should be recognized as the main criteria, making a comparison of the three kinds of business learning patterns, and aiming to explore more effective organizational leadership models.

\section{CONSENT FOR PUBLICATION}

Not applicable.

\section{AVAILABILITY OF DATA AND MATERIALS}

The data and materials used to support the findings of this study are available from the corresponding author [O.A.S] upon reasonable request.

\section{FUNDING}

This research received research funding from Korea University of Technology and Education (KOREATECH) under grant no. \#2020-0108.

\section{CONFLICT OF INTERESTS}

The authors declare no conflict of interest, financial or otherwise.

\section{ACKNOWLEDGEMENTS}

Declared none. 


\section{REFERENCES}

[1] M. Haghshenas, "Vaziri, urban sustainable transportation indicators for global comparison. -", Ecol. Indic., vol. 15, pp. 115-121, 2012. [http://dx.doi.org/10.1016/j.ecolind.2011.09.010]

[2] C. Samarnbutr, An Examination of Technological Capability Development in the Thailand Automobile Industry: The Role of the Thai Government Policy from 1960-2009., University of Portsmouth, 2012.

[3] B. Wattanadamring, A. Collins, and M. Snell, "Taking the thai trail: Attracting FDI via macro-level policy", J. Policy Model., vol. 36, no. 6, pp. 1135-1151, 2014.

[http://dx.doi.org/10.1016/j.jpolmod.2014.11.002]

[4] L. Kim, Imitation to innovation: The dynamics of Korea's technological learning. Boston, M.A.: Harvard Business School Press, 1997.T. Green, T. Groff, T. Jones. Introduction to knowledge management: KM in businesses., Butterworth-Heineman: Burlington, MA, 2013.

[5] Breakthrough Institute and Information Technology an Innovation Foundation, Rising tigers, sleeping giants, Oakland, Washington, 2009, pp. 43-49.

[6] G. Fei, L. Meng, and N. Yoshiteru, "Systems thinking on knowledge and its management: systems methodology for knowledge management", J. Knowl. Manage., vol. 6, no. 1, pp. 78-90, 2017.

[7] F. Lee, and M. Marx, "Managing creativity in small worlds", Calif. Manage. Rev., vol. 48, no. 4, pp. 6-27, 2016.

[8] S. Thalmann, Decision support framework for selecting techniques to prepare knowledge elements for adaptive use. Doctoral dissertation, University of Innsbruck, 2011

[9] G. Ryle, The concept of mind., The University of Chicago press: Chicago, 1949.

[10] M. Kalz, M. Specht, R. Nadolski, Y. Bastiaens, N. Leirs, and J.M. Pawlowski, "Competence-based management education with community-improved open educational resources", Proceedings of the 17th EDINEB conference: Crossing borders in Education and workbased learning, 2018 London. UK

[11] I. Nonaka, and H. Takeuchi, The knowledge-creating company., Oxford University press: Oxford, 1995.

[12] Applications of Management Science., vol. 18. Emerald Group Publishing Limited, Bingley, UK: Bingley, UK, 2016, pp. 57-84.K.D. Lawrence, and G. Kleinman Selected Multi-Criteria Green Vehicle Routing Problems, Chapter in Applications of Management Science

[13] J. Tobin, Can We Grow Faster? , Cowles Foundation Discussion Papers, 2020no. 1149, . Available at: http://cowles.yale.edu/ sites/default/files/files/pub/d11/d1149.pdf

[14] J. Rowley, "Knowledge organization for a new millennium: principles and processes", J. Knowl. Manage., vol. 4, no. 3, pp. 413-426, 2018.

[15] H. Dimitriou, and R. Gakenheimer, Urban Automotive in the Developing World: A Handbook of Policy and Practice., Edward Elgar Publishing: London, UK, 2011.

[http://dx.doi.org/10.4337/9781849808392]

[16] Innovative management: A conversation with Gary Hamel and Lowell Bryan // The McKinsey Quarterly, No 1

[17] K.D. Lawrence, G. Kleinman, "Multi-Objective Traveling Salesman and Transportation Problem with Environmental Aspects. Chapter in Applications of Management Science", In: Applications of Management Science., vol. 18. Emerald Group Publishing Limited, Bingley, UK: Bingley, UK, 2017, pp. 21-56. [http://dx.doi.org/10.1108/S0276-897620170000018002]

[18] G. Roos, and J. Roos, "Measuring your company's intellectual performance", Long Range Plann., vol. 30, no. 3, pp. 413-426, 2017. [http://dx.doi.org/10.1016/S0024-6301(97)90260-0]

[19] E. Lank, "Leveraging invisible assets: the human factor", Long Range Plann., vol. 30, no. 3, pp. 406-412, 2017.

[http://dx.doi.org/10.1016/S0024-6301(97)90258-2]

[20] A. Brooking. Intellectual capital for organizational leadership.,

[21] K. Natsuda, and J. Thoburn, Industrial Policy and the Development of the Automobile Industry in Thailand., RCAPS Working Paper, 2011, pp. 11-5.

[22] W.A. Bhatti, A. Zaheer, and K.U. Rehman, "The effect of knowledge management practices on organizational performance: A conceptual study", Afr. J. Bus. Manag., vol. 5, no. 7, pp. 2847-2853, 2019.

[23] K.H. Charles, "Review of the book The Automobile Age, by James J. Flink", J. Econ. Hist., vol. 49, no. 3, p. 779, 1989.

[24] J. Guimon, Policies to promote science-industry links and technology commercialization in emerging countries: the case of Kazakhstan's Technology, 2017.
[25] M.J. Gallivan, "Organizational adoption and assimilation of complex technological innovations: Development and application of a new framework", Data Base Adv. Inf. Syst., vol. 32, no. 3, pp. 51-85, 2011. [http://dx.doi.org/10.1145/506724.506729]

[26] D. Pojani, and D. Stead, "Sustainable urban automotive in the developing world: Beyond megacities.-", Sustainability, vol. 7, pp. 7784-7805, 2015.

[http://dx.doi.org/10.3390/su7067784]

[27] C. Cho, A. Kim, and M. Kim, Korea's Automotive Industry: Modularization of Korea's Development Experience., Ministry of Strategy and Finance: Republic of Korea, 2014.

[28] P. Ward, "The automobile industry of Southeast Asia: Malaysia and Thailand", J Asia Pacific Eco, vol. 14, no. 2, pp. 2-193, 2009.

[29] B. Sawik, and J. Faulin, "E. Prez-Bernabeu A multicriteria analysis for the green VRP: A case discussion for the distribution problem of a spanish retailer", Transp. Res. Procedia, vol. 22, pp. 305-313, 2017. [http://dx.doi.org/10.1016/j.trpro.2017.03.037]

[30] L. J. Cronbach, Coefficient alpha and the internal structure of tests., 1951. Psychometrika, 16, 297-334 (28,307 citations in Google Scholar as of $4 / 1 / 2016$ )

[http://dx.doi.org/10.1007/BF02310555]

[31] Available from: https://www.statista.com/statistics/269622/passenger car-production-in-asia

[32] J.D. Kim, and S.I. Hwang, The role of foreign direct investment in Korea's economic development. The role of foreign direct investment in East Asian Economic., University of Chicago Press, 2000, pp. 267-294.

[33] K.O.T.I. Knowledge Sharing, New Intermodal Automotive Systems in Korea (Report Issue 23)., The Korea Automotive Institute, 2017, pp. 78-98.

[34] B.T. Hayati, BPTT 3133 Technology Transfer in Business [Website]., 2019. Avaiable from : http://www.slideshare.net/nabilahnajah/

[35] S. Komolavanij, C. Jeenannunta, and V. Ammarapala, Innovation Capability of Thailand's Automotive Industrial Network. How to Enhance Innovation Capability with Internal and External Sources. ERIA Research Project Report 2010-9., ERIAH: Jakarta, 2011, pp. 219-272.

[36] Thailand Board of Investment. Thailand's Automotive Industry, $A$ guide to The Board of Investment [Brochure], 2019. Available at https://www.boi.go.th/upload/content/BOI-A\%20Guide EN.pdf

[37] N. Kaoru, Industrial Policy and the development of the automobile Industry in Thailand., RCAPS Working Paper: Ritsumeikan Asia Pacific University, 2011.

[38] Thailand Board of Investment, Thailand's Automotive Industry: The next-generation [Brochure] Available at: https://www.boi.go.th/.../ BOI-brochure\%202015-automotive-20150325 70298.pdf

[39] LAMONPHET APISITNIRAN Bangkok post, Available at: https://www.bangkokpost.com/business/1876654?cx placement=articl e\#cxrecs_s

[40] Automotive World, Special report: The ASEAN auto Industry., Automotive World Ltd.: Penarth, UK, 2018.

[41] J.D. Kim, and S.I. Hwang, The Role of Foreign Direct Investment in Korea's Economic Development. The Role of Foreign Direct Investment in East Asian Economic., University of Chicago Press, 2000, pp. 267-294.

[42] S. Naya, and P. Imada, Economic Success of the NIEs and ASEAN: Some Lessons for Latin America?, Southeast Asian Affairs, 1992, pp. 44-57.

[43] E. Vasconcellos, Urban Automotive, Environment, and Equity: The Case for Developing Countries., 2nd ed Earthscan: New York, NY, USA, 2013.

[44] M. Noland, and H. Pack, Industrial Policy in an Era of Globalization: Lessons from Asia., Institute of International Economics: Washington, DC, 2013.

[45] M. Tavakol, and R. Dennick, "Making sense of Cronbach's alpha", Int. J. Med. Educ., vol. 2, pp. 53-55, 2011

[http://dx.doi.org/10.5116/ijme.4dfb.8dfd] [PMID: 28029643]

[46] O. Shvetsova, "Innovative development of railway corporations in asian region: Estimating the impact of environment using comparative analysis of Korean and Chinese companies/ open", Transp. J., vol. 12, pp. 67-85, 2018.

[47] P. Heisig, "Harmonization of knowledge management - competing $160 \mathrm{KM}$ frameworks around the globe", J. Knowl. Manage., vol. 13, no. 4, pp. 4-31, 2019.

[http://dx.doi.org/10.1108/13673270910971798]

[48] H-C. Hobohm, Knowledge Management. Libraries and librarians taking up the challenge. IFLA publication series 108., Walter de 
Gruyter GmbH\&Co: Berlin, 2014.

[49] E. Daveport, and B. Cronin, "Knowledge management: semantic drift or conceptual shift?", J. Educ. Libr. Inf. Sci., vol. 41, no. 4, pp.
294-306, 2009.

[http://dx.doi.org/10.2307/40324047]

[50] Korea Railway Corporation [Website], http://www.letsHyundai.com/

(C) 2021 Shvetsova et al.

This is an open access article distributed under the terms of the Creative Commons Attribution 4.0 International Public License (CC-BY 4.0), a copy of which is available at: https://creativecommons.org/licenses/by/4.0/legalcode. This license permits unrestricted use, distribution, and reproduction in any medium, provided the original author and source are credited. 